\title{
Priorities, factors and alternatives involved in the choice of medical specialty - an empirical study on year sixth medical students
}

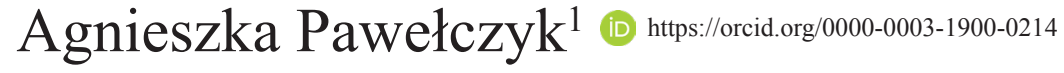

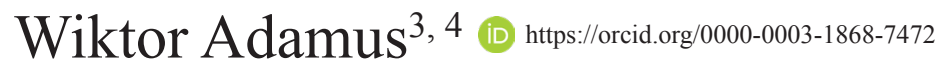 \\ Maciej Radek ${ }^{1}$ @i) https://orid.orgy0000-0003-3544-1482 \\ Tomasz Pawełczyk ${ }^{2}$ ๑ h htps://orid.orgy0000-0002-1421-2050
}

\begin{abstract}
${ }^{1}$ Department of Neurosurgery, Spine Surgery and Peripheral Nerves Surgery, Medical University of Łódź
${ }^{2}$ Department of Affective and Psychotic Disorders, Medical University of Łódź

${ }^{3}$ Institute of Economics, Finance and Management, Jagiellonian University, Kraków

${ }^{4}$ The College of Business and Entrepreneurship in Ostrowiec Świetokrzyski
\end{abstract}

Address for correspondence: Agnieszka Pawełczyk, Department of Neurosurgery, Spine Surgery and Peripheral Nerves Surgery, Medical University of Łódź, Żeromskiego 113, 90-549 Łódź, Poland, tel. +48 4263935 51, fax. +48426333000, agnieszka.pawelczyk@umed.lodz.pl

\section{Abstract}

Phenomenon. The process of career decision making by medical students has been the subject of many studies analyzing the choice. However, the studies have not analyzed determination of global priorities for the criteria of choice or alternatives regarding the choice of medical specialty. The goal of this paper is to determine the weights (priorities), factors and alternatives involved in the choice of specialty for year six medical students.

Approach. A sample of 202 final-year medical students at the Medical University was examined using Saaty's Analytic Hierarchy Process. During interviews, the students used the Saaty's scale to pair various factors influencing their choice of medical specialty. Analysis was performed to evaluate the crucial decisive criteria and various decisive models.

Findings. When choosing the medical specialty, the highest rank was given to "individual physician's aptitude and expected professional attainment" $(P=0.4748)$, followed by "the features of the medical specialty" $(P=0.3636)$ and "the process of training for the specialty" $(P=0.1616)$. The most important sub-criteria were "intellectual qualities and competencies useful in practicing the specialty", "place of work" and "opportunity to create one's own medical practice". A model of specialty choice was obtained. The most important criteria of choice were "opportunities for professional career in healthcare entities", "place of work", "opportunity to create one's own medical practice" and "expected income".

Insights. Understanding the factors influencing choice of specialty enables workforce planning to meet local and national healthcare needs. It also helps optimize the profile of medical education courses offered by medical universities. The results obtained, although limited in their generalisability, may support organizing specific curricula and strategies to encourage the choice of specialties in short supply.

\section{Key words: Analytic Hierarchy Process (aHP), alternatives, decision making, medical specialty, medical students, priorities}

Stowa kuczowe: proces decyzyjny, problem decyzyjny, specjalności medyczne, studenci medycyny 


\section{Introduction}

Effective workforce planning in the medical field is essential to meet local and national healthcare needs and to ensure the correct supply of medical professionals. It is particularly important when considering such issues as the under-supply of doctors in some specialties and localities, [1, 2] migration and dependency on international medical graduates, $[2,3]$ the high cost of employment, and underpayment of medical staff [4] as well as the duration of training and changes of specialty changes. [5-8] To allow effective planning of future employment in Medicine, it is first necessary to determine the factors which have the greatest influence on the choice of specialty for medical students.

A substantial body of literature already exists concerning the numerous factors influencing career preferences and decisions for medical professionals. These can be based on the individual characteristics of the medical student or doctor, the features of the specialty training process or the type of lifestyle and work connected with a certain medical specialty. The most commonly addressed personal characteristics include demographics [9-14], personality [9, 15-17], skills, values, aspirations [12, 18-21], academic and career opportunities [22] and expectations of family members [23-26]. As far as the training process itself is concerned, technological challenges, examples of physicians with the background, the possibility to obtain a residency position, the length of residency required, working hours and lifestyle during training all influence the decision to commence training [22, 27-32] as well as work-related hazards, such as infections from AIDS or hepatitis patients [33-35] and independent work $[12,32]$. When selecting a specialty medical students may also consider the various features of future work which may follow from it. The most important aspects in this regard are the prestige [22, 27, 36], the financial rewards after training [12, 13, 37], the type and number of patients $[12,13]$, the lifestyle after completion of residency [32, 38, 39], and also the possibility of establishing a practice $[23,40]$.

Although the majority of previous studies concerning influencing the choice of medical specialty have focused on quantitative comparisons, descriptive statistics and nonparametric statistics, they do not discuss the actual weight of each factor. Studies examining the factors influencing the career choices of Taiwanese students $[41,42]$, found that the most important factors were "personal preferences/work achievement" and "personal intelligence/ability/preference" followed by "career opportunities and lifestyle". One study showed that medical students were most concerned about obtaining affirmation of personal ability and a sense of accomplishment when selecting a specialty [41]. What is more, the majority regarded job position and future opportunity for promotion as second in importance. Quality of lifestyle was also an important concern for Taiwan medical students when selecting a specialty.

As the issue of medical specialty choice is a multiple criterion problem, influenced by many non-measurable and non-tangible (elusive) factors the method used to solve the problem should allow such analysis. In the area of solving multiple criterion problems the literature contains many different methods [43] e.g. the DEA (Data Envelopment Analysis), the AHP (Analytic Hierarchy Process), the ANP (Analytic Network Process), the MAPPACC (Multicriterion Analysis of Preferences by Means Pairwise Actions and Criterion Comparisons), artificial neural networks etc., however, the AHP and the ANP are considered the best. Thus, in this research, it was decided to refer to the multiple criterion decision making tool of the Analytic Hierarchy Process [44, 45] that is characterized by its simplicity, applicability to various areas of science and high effectiveness in problem solving. That method allows one to make a multi-faceted problem analysis and make a decision among many variants, leading to an effective solution of the problem. The AHP method is by far the most popular among all the above listed methods. It has the highest number of publications in the largest databases of scientific journals, such as ScienceDirect, Wiley, Scopus etc. In sole ScienceDirect database, the key words: 'analytic hierarchy process' generate 24,915 articles, and the abbreviation 'AHP' 17,453. Multi criteria analysismethods are mainly used to $[44,46,47]$ structure a complex decision problem, when multi-objectives or multiple criteria need to be considered; include heterogeneous sets of criteria and conflicting objectives; compare different management alternatives; conduct a more rational, transparent, and comprehensive analysis and include both qualitative and quantitative data in the decision model. In Health Sciences the method was used many times, for example M.J. Liberatore and R.L. Nydick [48] show its use in 50 scientific papers, however, they do not include papers concerning the determination of weights of factors and alternatives in the choice of medical specialty. Beside articles mentioned by Liberatore and Nydick [48] there were two papers by Chang et al. [49] and Wang et al. [42] published which used the AHP in the choice of specialty. Nevertheless, although Chang et al. [41] and Wang et al. [42] also use the AHP to examine a choice of specialty, these papers do not incorporate any determination of global priorities (meaning the individual influence of each sub-criterion on the process of choosing medical specialty) for the criteria or alternatives regarding the choice of medical specialty.

The AHP combines concepts from mathematics and psychology. The method was created by Thomas L. Saaty from Pittsburgh University (USA) in the early 1970s. A wide range of decision problems have been solved using it from virtually any area [50]. It differs from other multicriteria decision making methods in a number of aspects: (a) presentation of the problem structure in hierarchical form, with the overall goal at the top of the hierarchy as well as decision alternatives at its lowest level (Figure 1); (b) conducting pairwise comparisons of elements at each level of the hierarchical structure using the specially devised Saaty's preference scale (Table I); (c) introducing a relative assessment scale (priorities) for quantitative and qualitative comparisons. The significance and preferences of the various 
decision elements are linked in pairs with reference to the element which is immediately above in the hierarchy. On the basis of these comparisons local and global priorities are compared. Local priorities determine the relative importance of decision elements at each level of the hierarchical structure. They constitute a basis for the calculation of global priorities, which represent the share of each decision element from the various levels in the accomplishment of the main goal. The alternative with highest priority value is deemed to be the best and recommended for implementation in practice. All calculations are performed using the "Super Decisions" program (Adams and Saaty).

The differences in scales as well as measurement units are not a barrier in the application of the AHP since the method is based on direct significance degree comparisons as well as preferences of each decision elements pair without using physical units. This is why the AHP is also used with reference to analyses both quantitative as well as qualitative variables. For this reason the method can be used when we analyze a choice of medical specialty done by students. The AHP method has an advantage over a multi-dimensional scaling, for example Likert scale, in which the weights for each criterion are assigned subjectively, almost automatically, without much mental effort. In the method of T. Saaty, participants' evaluations are limited to verbal pairwise comparisons of adopted criteria which influence the main aim in the fundamental Saaty's scale. To determine the priorities (weights) for the criteria qualitative assessments made by evaluated people are changed to quantitative appraisals according to Saaty's scale. Subsequently, the logic of comparison criteria is checked on various stages of the research. In case one makes a mistake of the CR (consistency ratio) greater than $10 \%$, a re-interview is carried out with the participant. This way of testing preventes in part a subjective assessment.

At the time of writing this article, no similar research could be found evaluating the crucial decisive criteria and various decisive models for choosing a medical specialty. The aim of the present study was to investigate the decisive factors in the choice of medical specialty among final-year medical students and to examine the decision models used for choosing the specialty. Additionally, its purpose was to compare results from different countries and make cross-cultural comparisons.

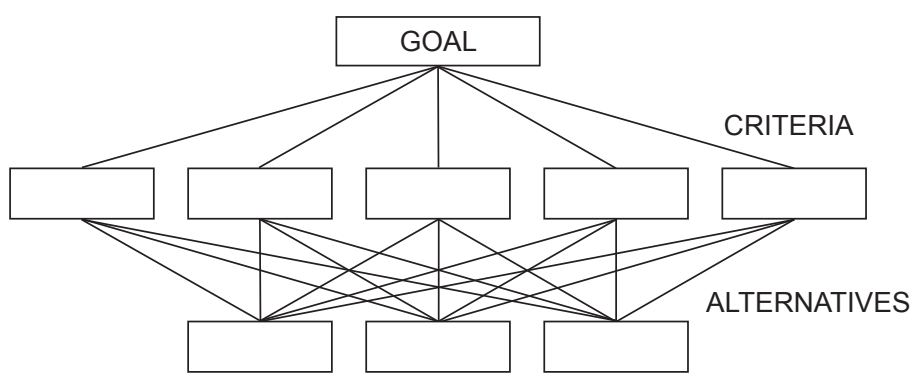

Figure 1. AHP decision hierarchy.

Source: Authors' own study based on T.L. Saaty, Decision Making for Leaders. The Analytic Hierarchy Process for Decisions in a Complex World, RWS Publications, Pittsburgh, PA 2001 [50].

\begin{tabular}{|c|c|c|}
\hline Scale & Definition & Explanation \\
\hline 1 & Equal importance/preference/like hood & Two elements contribute equally to the goal/parent element \\
\hline 3 & Weak dominance & Experience or judgment slightly favors one element over another \\
\hline 5 & Strong dominance & Experience or judgment strongly favors one element over another \\
\hline 7 & Demonstrated (very strong) dominance & $\begin{array}{l}\text { Experience or judgment strongly very strongly favors one element over } \\
\text { another (an element's dominance is demonstrated in practice) }\end{array}$ \\
\hline 9 & Absolute dominance & $\begin{array}{l}\text { The evidence favoring an element over another is affirmed to the highest } \\
\text { possible order }\end{array}$ \\
\hline $2,4,6,8$ & Intermediate values & Further subdivision or compromise is needed \\
\hline Reciprocals of the above & $\begin{array}{l}\text { If activity } i \text { has one of the above } \\
\text { nonzero numbers assigned to it when } \\
\text { compared with activity } j \text {, then } j \text { has } \\
\text { reciprocal value when compared with } i \text {. }\end{array}$ & i.e. If $x$ is 5 times $y$, then $y=x / 5$ \\
\hline Rationals & Rations arising from the scale & $\begin{array}{l}\text { If consistency were to be forced by obtaining } n \text { numerical values to span } \\
\text { the matrix }\end{array}$ \\
\hline
\end{tabular}

Table I. Saaty's fundamental comparison scale (1-9).

Source: Own study based on T.L. Saaty, Decision Making for Leaders. The Analytic Hierarchy Process for Decisions in a Complex World, RWS Publications, Pittsburgh, PA 2001 [50]. 


\section{Methods}

The study was performed on a group of 202 students (140 women and 62 men) at the Medical University in Poland (Medical University of Łódź), in their sixth and final year of the undergraduate medical course (the study group comprised all final year medical students). Information was gathered concerning demographical data and preferred medical specialties. Among the 202 students assessed, 195 had chosen one of the possible 24 specializations, while the remaining seven had not decided yet (Table II). All of the $6^{\text {th }}$ year students were asked to participate in this study after having finished their psychiatry classes. Most of them participated willingly and the participation rate was $98.7 \%$. Since it was the first study carried out with the application of the AHP its results could be treated as preliminary. The sample cannot be treated as representative for the population of Polish or European students.

While comparing the criteria pairwise, the students were asked to verbally describe the subjective importance of the given criterion or sub-criterion of their choice of medical specialty. They made those comparisons speaking to each questionnaire item comparing two criteria and it was marked with them on each item (scale). In subsequent calculations, this was used as a basis for verbal opinions, which were converted into numerical scores to quantify the comparative importance of the main criteria and sub-criteria.

The following steps (stages) were adopted to determine the factors influencing the choice of medical specialty. Firstly, the problem was posed, in this case,

\begin{tabular}{|c|c|c|c|}
\hline & Medical specialty & $\begin{array}{l}\text { Number } \\
\text { of students }\end{array}$ & $\begin{array}{l}\text { Percentage } \\
\text { of total (\%) }\end{array}$ \\
\hline 1. & Surgery & 24 & 11.9 \\
\hline 2. & Paediatrics & 23 & 11.4 \\
\hline 3. & Internal Medicine & 17 & 8.4 \\
\hline 4. & Gynaecology & 17 & 8.4 \\
\hline 5. & Cardiology & 16 & 7.9 \\
\hline 6. & Anaesthesiology & 16 & 7.9 \\
\hline 7. & Ophthalmology & 13 & 6.4 \\
\hline 8. & Dermatology & 11 & 5.4 \\
\hline 9. & Radiology & 9 & 4.5 \\
\hline 10. & Psychiatry & 8 & 4.0 \\
\hline 11. & Neurology & 7 & 3.5 \\
\hline 12. & Orthopaedics & 6 & 3.0 \\
\hline 13. & ENT & 5 & 2.5 \\
\hline 14. & Family medicine & 4 & 2.0 \\
\hline 15. & Oncology & 4 & 2.0 \\
\hline 16. & Urology & 3 & 1.5 \\
\hline 17. & Haematology & 3 & 1.5 \\
\hline 18. & Endocrinology & 2 & 1.0 \\
\hline 19. & Emergency medicine & 2 & 1.0 \\
\hline 20. & Cardiosurgery & 1 & 0.5 \\
\hline 21. & Contagious diseases & 1 & 0.5 \\
\hline 22. & Rehabiltation & 1 & 0.5 \\
\hline 23. & Nephrology & 1 & 0.5 \\
\hline 24. & Neurosurgery & 1 & 0.5 \\
\hline \multirow[t]{2}{*}{25.} & No preference & 7 & 3.5 \\
\hline & $\sum=$ & 202 & 100.0 \\
\hline
\end{tabular}

Table II. Medical specialty chosen by final-year medical students. Source: Own study.

Making the decision about the choice of medical specialty

Physician's aptitude and expected professional attainment

\begin{tabular}{|c|}
\hline $\begin{array}{c}\text { Intellectual qualities and } \\
\text { competencies useful } \\
\text { in practicing the specialty }\end{array}$ \\
\hline $\begin{array}{c}\text { The prospects of } \\
\text { scientific development } \\
\text { at the university }\end{array}$ \\
\hline $\begin{array}{c}\text { Opportunities for } \\
\text { professional career } \\
\text { in healthcare entities }\end{array}$ \\
\hline $\begin{array}{c}\text { Family and social } \\
\text { expectations }\end{array}$ \\
\hline
\end{tabular}

Process of training for the specialty

The authority of specialist physicians

The possibility of carrying out medical procedures

The risk of infection

The time needed to acquire specialist skills

Passion and possibility of independent work
The features of the medical specialty

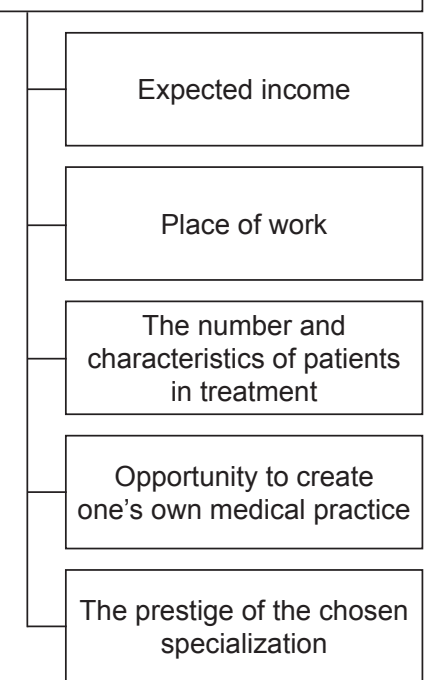

Figure 2. The hierarchy tree for the choice of medical specialty by final-year medical students. Source: Own study. 
the determination of the factors and their priorities (weights) influencing the choice of medical specialty by final year medical students. Secondly, the main goal was identified, this being the optimal choice of medical specialty by final-year medical students. Thirdly, the internal and external factors determining the process of choosing the medical specialty were discovered. Fourthly, the multi-level structure of the problem was constructed in the form of a hierarchy tree comprising the main goal, main criteria, sub-criteria and so on for each factor (Figure 2). A literature search was performed by using PUBMED and using search words: "medical students AND career choice", "medical specialty preference", "medical specialty choice", "students' choice of specialty". Grounded on factors from the literature a decision hierarchy tree was constructed and the questionnaire for interviews prepared. Three main criteria and within their framework sub-criteria were chosen according to the published research.

Three characteristics were adopted as the main criteria: individual physician's aptitude and expected professional attainment, the process of training for the specialization, and the features of the medical specialty. These characteristics were assigned the following definitions. "Individual physician's aptitude and expected professional attainment": this term is understood in different senses by many researchers, but relates primarily to the relatively fixed qualities of the physician's personality, his intellectual potential, aspirations and expectations concerning his family or social circle. "The process of training for the specialty" concerns the factors associated with the training process: it is dependent on the medical procedures to be performed and any associated possibility of harm to the student, the qualities of instructors/directors of the specialty, as well the length of time needed and difficulty of acquiring the necessary medical skills. The third characteristic, "The features of the medical specialty" is associated with the place and organization of work of the specialist physician, expected income and prestige relating to the given specialty, the type and number of patients.

The next step was to define the sub-criteria within the framework of the adopted main criteria. The following sub-criteria were adopted for the criterion "Individual physician's aptitude and expected professional attainment": a. Intellectual qualities and competencies useful in practicing the specialization - knowledge, experience, situations which demand the consideration of various types of information before formulating (a) Conclusion, relatively fixed personal qualities including emotional and manual ones, (b) The prospects of professional development at the university - research and teaching activities, (c) Opportunities for professional career in healthcare entities - consisting of pursuits connected to the professional sphere, which are shaped by a person's value hierarchy, (d) Family and social expectations - perceived expectations of relatives and/or society concerning the choice of specialization. In the criterion "The process of training for the specialty", the following sub-criteria were distinguished: (a) The authority of specialist physicians
- positive examples of behavior, (b) Passion and possibility of independent work, (c) The possibility of carrying out medical procedures - the opportunity to practice the diagnostic process, or conduct treatment including the performance of surgical operations, (d) The risk of infection - the possibility of getting infected by a virus, e.g. HIV or HCV, (e) The time needed to acquire specialist skills. Finally, the following sub-criteria were adopted for the third criterion "The features of the medical specialty": (a) Expected income - financial gain from the work done in the medical specialization, (b) Place of work - the opportunity to work in an office, a health center or hospital, or at a university, (c) The number of patients in treatment and their characteristics - the variety of patients with different illnesses with varying degrees of advancement (for example, emergency and serious conditions, chronic illnesses, less serious illnesses, the type of medical procedures) elements of prevention, diagnosis, treatment and rehabilitation to be performed by the physician, (d) Opportunity for the graduate to start a medical practice the mode and hours of work, regulated hours of work, duty hours and time for family, (e) The prestige of the chosen specialization (a subjective criterion of stratification, consisting of emotionally-based evaluation and objective stratification factors) - the level of education, profession, lifestyle and income.

Following this, the dominance (prevalence) of the main criteria was defined within the framework of the hierarchical structure by making pairwise comparisons for each option against all others, with regard to their importance in choosing the specialty [51]. The evaluators of the criteria were expected to answer a series of questions: which of the criterion ranks has the greatest importance for the student on the process of choosing a medical specialty, which of the sub-criteria is more important in relation to the given criterion, and to what degree are they more important on the scale from equally important to absolute dominance. The evaluator marked the dominance of one criterion above another on the verbal scale from weak to absolute (extreme) dominance, using a pairwise comparison table. If one criterion did not outweigh another, i.e. two criteria were equivalent in the student's opinion, the evaluator marked them as being of equal dominance, writing this fact in the dominance table as "equilibrium".

The preferences for sub-criteria (intensity level) were then defined within the framework of the hierarchical structure. This was performed by pairwise comparison of their importance in relation to the value of each main criterion, using the Saaty fundamental preference scale. Verbal opinions about the comparative importance of the main criteria were quantified by conversion into numerical scores according to Saaty. The comparative importance of the sub-criteria was quantified based on the verbal opinions. Priorities (weights) were then calculated, local from the interval $[>0,<1]$ for each criterion $\left(P_{K}\right)$ and sub-criterion $\left(P_{S}\right)$, by normalizing eigenvectors for the comparison matrix. The computed weights allow the criteria to be ranked according to their importance in choosing the medical specialty. 


\section{Resullts}

Each criterion was compared against all others with regard to the main goal for all students from the sample. The comparison itself was based on the computation of the geometrical mean for answers from each respective specialization group.

The following priorities were obtained for the main criteria. Concerning the choice of medical specialty, the highest rank was given to "Individual physician's aptitude and expected professional attainment" $(P=0.4748)$, with the following sub-criteria: intellectual qualities and competencies useful in carrying out the specialty, prospects of scientific development at the university, opportunities for professional career in healthcare entities, family and social expectations. This was followed by "The features of the medical specialty" $(P=0.3636)$. Of the three analyzed main criteria, the least important was "The process of training for the specialty" $(P=0.1616)$. The sum of all analyzed priorities in relation to a main goal equaled to $1(100 \%)$ and the estimated discrepancy coefficients were lower than $10 \%$, which was the precondition for further analysis performed with the 'Super Decisions' software.
For "Individual physician's aptitude and expected professional attainment", the highest-ranked sub-categories were as follows: "Intellectual qualities and competencies useful in carrying out the specialization" $(P=0.4872)$ "Opportunities for professional career in healthcare entities" $(P=0.2643)$, "The prospects of scientific development at the university" $(P=0.1431)$, "Family and social expectations" $(P=0.1053)$.

For the main criterion "The process of training for the specialty", the most important sub-category was "Passion and possibility of independent work" $(P=0.3738)$, followed by "Possibility of carrying out medical procedures" $(P=0.2696)$, "The authority of the specialist physician" $(P=0.1596)$, "The time and difficulty of obtaining the specialization" $(P=0.1596)$ and finally, "The risk of infection" $(P=0.0751)$.

For "The features of medical specialty", the highest priority was awarded to the sub-criterion "Place of work" ( $P=0.3032)$, followed closely by "Opportunity to create one's own medical practice" $(P=0.2243)$. The sub-criteria "Expected income", "Prestige of the chosen specialty", "The number and characteristics of treated patients" were given similar priorities ranging from $P=0.1520$ to $P=0.1673$.

\begin{tabular}{|c|c|c|c|}
\hline Criteria (Local Priorities $-\boldsymbol{P}_{k}$ ) & Sub-criteria & Local priorities $\left(\boldsymbol{P}_{s}\right)$ & Global priorities $\left(\boldsymbol{P}_{g}\right)$ \\
\hline \multirow{5}{*}{$\begin{array}{l}\text { Individual physician's aptitude and expected } \\
\text { professional attainment } \\
\left(\boldsymbol{P}_{\boldsymbol{k}}=\mathbf{0 . 4 7 4 8}\right)\end{array}$} & $\begin{array}{l}\text { Intellectual qualities and competencies useful } \\
\text { in practicing the specialty }\end{array}$ & 0.4872 & 0.2313 \\
\hline & $\begin{array}{l}\text { The prospects of scientific development at } \\
\text { the university }\end{array}$ & 0.1431 & 0.0679 \\
\hline & $\begin{array}{l}\text { Opportunities for professional career in health- } \\
\text { care entities }\end{array}$ & 0.2643 & 0.1255 \\
\hline & Family and social expectations & 0.1054 & 0.0501 \\
\hline & & $\Sigma=1.0$ & $\Sigma=0.4748$ \\
\hline \multirow{6}{*}{$\begin{array}{l}\text { The process of training for the specialty } \\
\left(\boldsymbol{P}_{\boldsymbol{k}}=\mathbf{0 . 1 6 1 6}\right)\end{array}$} & The authority of specialist physicians & 0.1596 & 0.0258 \\
\hline & $\begin{array}{l}\text { The possibility of carrying out medical } \\
\text { procedures }\end{array}$ & 0.2696 & 0.0436 \\
\hline & The risk of infection & 0.0751 & 0.0121 \\
\hline & The time needed to acquire specialist skills & 0.1220 & 0.0197 \\
\hline & Passion and possibility of independent work & 0.3737 & 0.0604 \\
\hline & & $\Sigma=1.0$ & $\Sigma=0.1616$ \\
\hline \multirow{5}{*}{$\begin{array}{l}\text { The features of the medical specialty } \\
\left(\boldsymbol{P}_{\boldsymbol{k}}=\mathbf{0 . 3 6 3 6}\right)\end{array}$} & Expected income & 0.1520 & 0.0553 \\
\hline & Place of work & 0.3032 & 0.1103 \\
\hline & $\begin{array}{l}\text { The number and characteristics of patients } \\
\text { in treatment }\end{array}$ & 0.1673 & 0.0608 \\
\hline & $\begin{array}{l}\text { Opportunity to create one's own medical } \\
\text { practice }\end{array}$ & 0.2243 & 0.0816 \\
\hline & The prestige of the chosen specialty & 0.1533 & 0.0557 \\
\hline$\Sigma=1.0000$ & & $\Sigma=1.0$ & $\Sigma=0.3636$ \\
\hline Sum & & & $\Sigma=1.0$ \\
\hline
\end{tabular}

Table III. The criteria and sub-criteria examined in the process of choosing medical specialty by final year medical students, and their global priorities.

Source: Own study. 
Consistency indicators (CR) indicating the logical consistency of verbal pairwise comparisons conducted in this research study did not exceed $10 \%$, fulfilling the requirements of Saaty's method. The eigenvalue approach of the AHP provides a measure for the consistency of the judgments (consistency ratio), aiming to improve the coherence among redundant judgments [46]. Computation of consistency indicators CR (logical consistency of verbal pairwise comparisons) to the main criteria and partial sub-criteria provides a measure of the probability that the pairwise comparison matrix was filled in purely at random. The number 0.2 says that there is a $20 \%$ chance that the decision maker will answer the questions in a random manner [52]. The inconsistency measures the logical inconsistency of judgments and is useful for identifying possible errors in judgments as well as actual inconsistencies in the judgments themselves. In general, the consistency ratio should be less than 0.1 [53]. If the consistency ratio is greater than $0.1(10 \%)$ then the students have to re-evaluate their judgments in pairwise comparison matrix until the ratio is finally less than $0.1(10 \%)$.

Table III lists the local priorities for the main criteria and their sub-criteria. Global priorities for each sub-criterion are also presented. The local priority for a criterion indicates the influence on the main objective of a particular group of factors in the decision-making process. Thus, for example, the factors in "The features of the medical specialty" as a whole account for $36.36 \%$ of the choice of medical specialty, while those constituting "The process of training for the specialty" account for $16.16 \%$. The local priorities for sub-criteria shown in Table IV indicate the influence of each of the sub-criteria on choosing the specialty in the decision-making process. In this way, for example, "Family and/or social expectations" have a $10.54 \%$ influence on "Individual physician's aptitude and expected professional attainment", while "Opportunities for professional career in healthcare entities" account for $26.43 \%$ of "Individual physician's aptitude and expected professional attainment".

In order to compute the influence of each sub-criterion on the process of choosing a medical specialty, its global priority was estimated. It is calculated by multiplying the local priority for the main criterion by the local priority of the given sub-criterion. Thus, for example, the global priority for "Opportunities for professional career in healthcare entities" results from the multiplication of the local priority for "Individual physician's aptitude and expected professional attainment" $(P=0.4748)$

\begin{tabular}{|c|c|c|c|c|c|c|c|c|c|c|}
\hline \multirow{2}{*}{$\begin{array}{c}\text { Criteria/sub-criteria } \\
\downarrow\end{array}$} & \multicolumn{2}{|c|}{ All students } & \multicolumn{2}{|c|}{ Women } & \multicolumn{2}{|c|}{ Men } & \multicolumn{2}{|c|}{ Surgery } & \multicolumn{2}{|c|}{ Paediatrics } \\
\hline & $P_{l}$ & $\boldsymbol{P}_{g}$ & $P_{I}$ & $\boldsymbol{P}_{g}$ & $P_{l}$ & $\boldsymbol{P}_{g}$ & $P_{l}$ & $\boldsymbol{P}_{g}$ & $P_{l}$ & $\boldsymbol{P}_{g}$ \\
\hline $\begin{array}{l}\text { Individual physician's aptitude and ex- } \\
\text { pected professional attainment }\end{array}$ & 0.475 & & 0.476 & & 0.472 & & 0.232 & & 0.530 & \\
\hline $\begin{array}{l}\text { Intellectual qualities and competencies useful } \\
\text { in practicing the specialty }\end{array}$ & 0.487 & 0.231 & 0.493 & 0.235 & 0.473 & 0.223 & 0.424 & 0.098 & 0.532 & 0.282 \\
\hline $\begin{array}{l}\text { The prospects of scientific development at } \\
\text { the university }\end{array}$ & 0.143 & 0.068 & 0.141 & 0.067 & 0.147 & 0.069 & 0.193 & 0.044 & 0.130 & 0.069 \\
\hline $\begin{array}{l}\text { Opportunities for professional career } \\
\text { in healthcare entities }\end{array}$ & 0.264 & 0.126 & 0.265 & 0.126 & 0.266 & 0.126 & 0.270 & 0.063 & 0.229 & 0.121 \\
\hline Family and social expectations & 0.105 & 0.050 & 0.101 & 0.048 & 0.114 & 0.054 & 0.113 & 0.026 & 0.109 & 0.058 \\
\hline The process of training for the specialty & 0.162 & & 0.158 & & 0.169 & & 0.117 & & 0.145 & \\
\hline The authority of specialist physicians & 0.160 & 0.026 & 0.151 & 0.024 & 0.181 & 0.031 & 0.136 & 0.016 & 0.242 & 0.035 \\
\hline $\begin{array}{l}\text { The possibility of carrying out medical } \\
\text { procedures }\end{array}$ & 0.270 & 0.044 & 0.265 & 0.042 & 0.278 & 0.047 & 0.428 & 0.050 & 0.185 & 0.027 \\
\hline The risk of infection & 0.075 & 0.012 & 0.073 & 0.011 & 0.078 & 0.013 & 0.049 & 0.006 & 0.068 & 0.010 \\
\hline The time needed to acquire specialist skills & 0.122 & 0.020 & 0.118 & 0.019 & 0.131 & 0.022 & 0.087 & 0.010 & 0.113 & 0.016 \\
\hline Passion and possibility of independent work & 0.374 & 0.060 & 0.393 & 0.062 & 0.332 & 0.056 & 0.300 & 0.035 & 0.391 & 0.057 \\
\hline The features of the medical specialty & 0.364 & & 0.366 & & 0.359 & & 0.651 & & 0.325 & \\
\hline Expected income & 0.152 & 0.055 & 0.128 & 0.047 & 0.224 & 0.080 & 0.139 & 0.090 & 0.140 & 0.046 \\
\hline Place of work & 0.303 & 0.110 & 0.328 & 0.120 & 0.248 & 0.089 & 0.236 & 0.153 & 0.242 & 0.079 \\
\hline $\begin{array}{l}\text { The number and characteristics of patients } \\
\text { in treatment }\end{array}$ & 0.167 & 0.061 & 0.171 & 0.062 & 0.149 & 0.053 & 0.164 & 0.106 & 0.240 & 0.078 \\
\hline $\begin{array}{l}\text { Opportunity to create one's own medical } \\
\text { practice }\end{array}$ & 0.224 & 0.082 & 0.226 & 0.083 & 0.216 & 0.078 & 0.228 & 0.148 & 0.220 & 0.072 \\
\hline The prestige of the chosen specialty & 0.153 & 0.056 & 0.147 & 0.054 & 0.163 & 0.059 & 0.233 & 0.153 & 0.158 & 0.051 \\
\hline$\Sigma=$ & & 1.0 & & 1.0 & & 1.0 & & 1.0 & & 1.0 \\
\hline
\end{tabular}

Table IV. The local and global weights for criteria and sub-criteria for all of the students, both sexes and in the two specialty most frequently chosen by medical students of the Medical University (Local priorities $-P_{l}$, Global priorities - Pg).

Source: Own study. 


\begin{tabular}{|l|l|l|l|}
\hline \multicolumn{1}{|c|}{ Model A } & \multicolumn{1}{|c|}{ Model B } & \multicolumn{1}{|c|}{ Model C } \\
\hline $\begin{array}{l}\text { The prestige of the chosen } \\
\text { specialty }\end{array}$ & $\begin{array}{l}\text { The prestige of the chosen } \\
\text { specialty }\end{array}$ & Expected income & Place of work \\
\hline Expected income & $\begin{array}{l}\text { The number and characteristics of } \\
\text { patients }\end{array}$ & $\begin{array}{l}\text { The number and characteristics of } \\
\text { patients }\end{array}$ & $\begin{array}{l}\text { Characteristics of medical } \\
\text { procedures }\end{array}$ \\
\hline Place of work & procedures & $\begin{array}{l}\text { The number and characteristics of } \\
\text { patients }\end{array}$ \\
\hline $\begin{array}{l}\text { The possibility of carrying out } \\
\text { medical procedures }\end{array}$ & The risk of a lawsuit & Possibility of a professional career & $\begin{array}{l}\text { Passion and possibility of inde- } \\
\text { pendent work }\end{array}$ \\
\hline The risk of infection & $\begin{array}{l}\text { The time needed to acquire spe- } \\
\text { cialist skills }\end{array}$ & The risk of infection & $\begin{array}{l}\text { The time needed to acquire spe- } \\
\text { cialist skills }\end{array}$ \\
\hline $\begin{array}{l}\text { Difficulties in acquiring practical } \\
\text { skills }\end{array}$ & $\begin{array}{l}\text { Passion and possibility of inde- } \\
\text { pendent work }\end{array}$ & $\begin{array}{l}\text { The possibility of carrying out } \\
\text { medical procedures }\end{array}$ & $\begin{array}{l}\text { Difficulties in acquiring practical } \\
\text { skills }\end{array}$ \\
\hline Personality traits & Family expectations & $\begin{array}{l}\text { Scientific and teaching work at } \\
\text { university }\end{array}$ & Personality traits \\
\hline Family expectations & $\begin{array}{l}\text { Scientific and teaching work at } \\
\text { university }\end{array}$ & Career aspirations & Relationship with the patient \\
\hline $\begin{array}{l}\text { Intellectual qualities and } \\
\text { competencies }\end{array}$ & Relationship with the patient & Family expectations & Career aspirations \\
\hline
\end{tabular}

Table V. Characteristics of decision alternatives for choosing medical specialty by final year medical students.

Source: Own study.

\begin{tabular}{|c|c|c|c|c|c|}
\hline Sub-criteria & Global priorities $\left(\boldsymbol{P}_{g}\right)$ & $\begin{array}{c}\text { Model } \\
\text { A }\end{array}$ & $\begin{array}{l}\text { Model } \\
\text { B }\end{array}$ & $\begin{array}{l}\text { Model } \\
\text { C }\end{array}$ & $\begin{array}{c}\text { Model } \\
\text { D }\end{array}$ \\
\hline $\begin{array}{l}\text { Individual physician's aptitude and expected profes- } \\
\text { sional attainment }\end{array}$ & 0.2313 & $\begin{array}{c}0.417 \\
(0.096)\end{array}$ & $\begin{array}{c}0.083 \\
(0.019)\end{array}$ & $\begin{array}{c}0.083 \\
(0.019)\end{array}$ & $\begin{array}{c}0.417 \\
(0.096)\end{array}$ \\
\hline $\begin{array}{l}\text { Intellectual qualities and competencies useful in practicing } \\
\text { the specialty }\end{array}$ & 0.0679 & $\begin{array}{c}0.096 \\
(0.007)\end{array}$ & $\begin{array}{c}0.368 \\
(0.025)\end{array}$ & $\begin{array}{c}0.368 \\
(0.025)\end{array}$ & $\begin{array}{r}0.169 \\
(0.011)\end{array}$ \\
\hline The prospects of scientific development at the university & 0.1255 & $\begin{array}{c}0.143 \\
(0.018)\end{array}$ & $\begin{array}{c}0.143 \\
(0.018)\end{array}$ & $\begin{array}{c}0.571 \\
(0.072)\end{array}$ & $\begin{array}{c}0.143 \\
(0.018)\end{array}$ \\
\hline \multirow[t]{2}{*}{ Opportunities for professional career in healthcare entities } & 0.0501 & $\begin{array}{c}0.300 \\
(0.015)\end{array}$ & $\begin{array}{c}0.300 \\
(0.015)\end{array}$ & $\begin{array}{c}0.300 \\
(0.015)\end{array}$ & $\begin{array}{c}0.100 \\
(0.005)\end{array}$ \\
\hline & $\Sigma=0.4748$ & & & & \\
\hline The process of training for the specialty & 0.0258 & $\begin{array}{c}0.375 \\
(0.010)\end{array}$ & $\begin{array}{c}0.375 \\
(0.010)\end{array}$ & $\begin{array}{c}0.125 \\
(0.003)\end{array}$ & $\begin{array}{c}0.125 \\
(0.003)\end{array}$ \\
\hline The authority of specialist physicians & 0.0436 & $\begin{array}{c}0.400 \\
(0.017)\end{array}$ & $\begin{array}{c}0.100 \\
(0.004)\end{array}$ & $\begin{array}{c}0.400 \\
(0.017)\end{array}$ & $\begin{array}{r}0.100 \\
(0.004)\end{array}$ \\
\hline The possibility of carrying out medical procedures & 0.0121 & $\begin{array}{c}0.375 \\
(0.004)\end{array}$ & $\begin{array}{c}0.125 \\
(0.002)\end{array}$ & $\begin{array}{c}0.375 \\
(0.004)\end{array}$ & $\begin{array}{c}0.125 \\
(0.002)\end{array}$ \\
\hline The risk of infection & 0.0197 & $\begin{array}{c}0.100 \\
(0.002)\end{array}$ & $\begin{array}{c}0.400 \\
(0.008)\end{array}$ & $\begin{array}{c}0.100 \\
(0.002)\end{array}$ & $\begin{array}{c}0.400 \\
(0.008)\end{array}$ \\
\hline \multirow[t]{2}{*}{ The time needed to acquire specialist skills } & 0.0604 & $\begin{array}{c}0.083 \\
(0.005)\end{array}$ & $\begin{array}{c}0.417 \\
(0.025)\end{array}$ & $\begin{array}{c}0.083 \\
(0.005)\end{array}$ & $\begin{array}{c}0.417 \\
(0.025)\end{array}$ \\
\hline & $\Sigma=0.1616$ & & & & \\
\hline The features of the medical specialty & 0.0553 & $\begin{array}{c}0.375 \\
(0.021) \\
\end{array}$ & $\begin{array}{r}0.0125 \\
(0.007)\end{array}$ & $\begin{array}{c}0.375 \\
(0.021)\end{array}$ & $\begin{array}{c}0.125 \\
(0.007) \\
\end{array}$ \\
\hline Expected income & 0.1103 & $\begin{array}{c}0.318 \\
(0.035)\end{array}$ & $\begin{array}{c}0.045 \\
(0.005)\end{array}$ & $\begin{array}{c}0.318 \\
(0.035)\end{array}$ & $\begin{array}{c}0.318 \\
(0.035)\end{array}$ \\
\hline Place of work & 0.0608 & $\begin{array}{c}0.063 \\
(0.004)\end{array}$ & $\begin{array}{c}0.313 \\
(0.019)\end{array}$ & $\begin{array}{c}0.313 \\
(0.019)\end{array}$ & $\begin{array}{c}0.313 \\
(0.019)\end{array}$ \\
\hline The number and characteristics of patients in treatment & 0.0816 & $\begin{array}{c}0.083 \\
(0.007)\end{array}$ & $\begin{array}{c}0.083 \\
(0.007)\end{array}$ & $\begin{array}{c}0.417 \\
(0.034)\end{array}$ & $\begin{array}{c}0.417 \\
(0.034)\end{array}$ \\
\hline \multirow[t]{2}{*}{ Opportunity to create one's own medical practice } & 0.0557 & $\begin{array}{c}0.417 \\
(0.023) \\
\end{array}$ & $\begin{array}{c}0.417 \\
(0.023) \\
\end{array}$ & $\begin{array}{c}0.083 \\
(0.005) \\
\end{array}$ & $\begin{array}{c}0.083 \\
(0.005)\end{array}$ \\
\hline & $\Sigma=0.3636$ & & & & \\
\hline MODELS & $\Sigma=1.0000$ & 0.264 & 0.187 & 0.276 & 0.274 \\
\hline
\end{tabular}

Table VI. A comparison of the developed models with regard to all sub-criteria in the process of choice of medical specialty by final year medical students.

Source: Own study. 
by the local priority of "Opportunities for professional career in healthcare entities" $(P=0.1431)$. The calculated global priority is thus equal to $\boldsymbol{P}_{g}=\boldsymbol{P}_{l} \times \boldsymbol{P}_{s}, \boldsymbol{P}_{g}=\mathbf{0 . 4 7 4 8}$ $\times \mathbf{0 . 1 4 3 1}=\mathbf{0 . 0 6 7 9}$.

The results from Table IV indicate that women and men use similar criteria in choosing the medical specialty, as the global priorities for the two groups are not significantly different. When choosing Surgery as a specialty, the students rated the criteria "Possibility of creating one's own medical practice", "Prestige of the chosen specialty" and "Place of work" most highly. When choosing "Pediatrics", the respondents chose "Intellectual qualities and competencies useful in practicing the specialty", "Opportunities for professional career in healthcare entities" and "Place of work".

Decision alternatives (models of choice) were then developed. To determine what guides final year medical students in their choices of medical specialty, four hypothetical models (decision alternatives) were developed based on available literature. These were constructed based on the three most significant sub-criteria from each group of main criteria. The following models of choice of medical specialization were proposed (see Table V).

Criteria of the Model A have been discussed by [22, $33,37]$, of Model B by [12, 27, 36], of Model C by [12, $13,37]$, and of Model D by [22, 27]. To choose the best model, all models were compared with each other with regard to all 15 sub-criteria present in the hierarchy tree (Table VI).

The AHP method was found to provide an objective way of choosing the best alternative. Of the four examined models, the most suitable for choosing medical specialty was found to be Model C, followed closely by Model D and then Model A, with Model B being the least suitable (Figure 3).

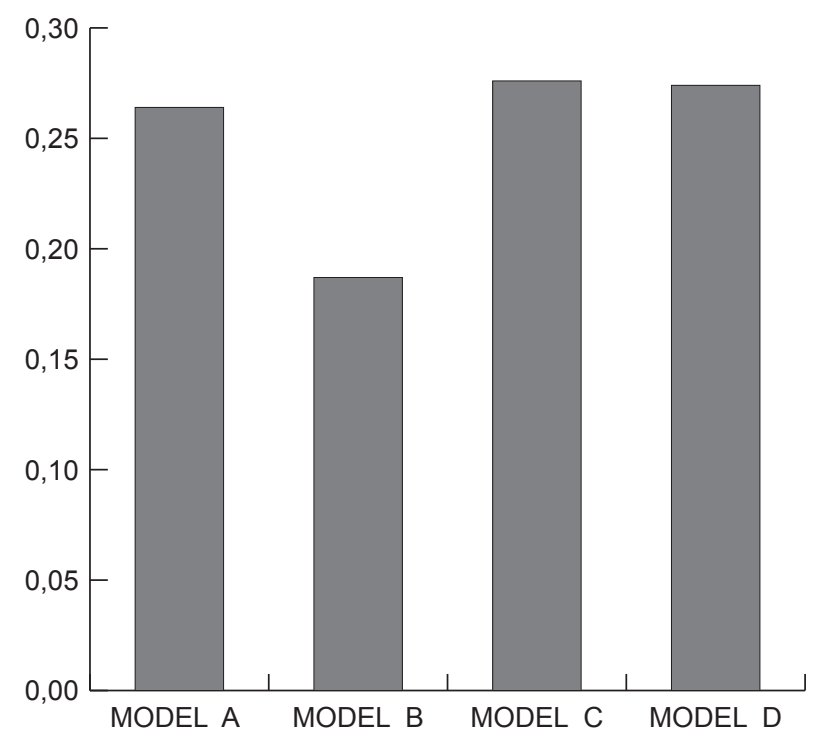

Figure 3. A comparison of global models of medical specialty by final-year medical students.

Source: Own study.

\section{Discussion}

The choice of specialty by medical students is a multidimensional process including many factors. Statistical analysis showed that the chosen criteria and sub-criteria influence the choice regardless of age or sex. The most important criterion for choosing the specialty was "Individual physician's aptitude and expected professional attainment", followed by "the features of the medical specialty", with "The process of training for the specialty" being the least significant. The results imply that evaluated medical students are most concerned about the development of their own personality traits, and the fulfillment of their intellectual abilities and aspirations when choosing a specialty. This was also reflected in the students' choice of sub-criterion "Intellectual qualities and competencies useful in practicing the specialty". In addition, "Place of work" and "Opportunity to create one's own medical practice" influenced their choices strongly. In sub-criteria of "the process of specialty training", the respondents emphasize "Passion and chance to work independently", although it was the least important option. It can be assumed that personal development, independent work and the chance to open a private practice had the greatest influence on choosing the specialty.

Surgery and Pediatrics were declared as the most interesting medical specialties. Those preferring Surgery chose "Opportunity to create one's own medical practice", "The prestige of the chosen specialty" and "Place of work" as the most influential criteria for their decision. Whereas for those interested in Pediatrics, most impacting factors were the development of "Intellectual qualities and competencies useful in practicing the specialty", "Opportunities for professional career in healthcare entities" and "Place of work". What is more, of the four models of specialty preference analyzed, the highest priority was achieved by the one whose most important criteria were "Opportunities for professional career in healthcare entities", "Place of work", "Opportunity to create one's own medical practice" and "Expected income". It indicates that when making a specialty choice, medical students regard working conditions and economic factors as the most significant factors.

Our results partly confirm those of Taiwanese researches [41] and [42] in that "Individual physician's aptitude and expected professional attainment" was given the greatest importance, followed by "The features of the medical specialty" and "The process of training for medical specialty". Medical students regard personal development, position at work and opportunity for promotion as having the greatest influence when choosing their specialty. However, while the third most important factor in the Taiwanese study was "Lifestyle after completion of training", our study found it to be "Passion and possibility of independent work" followed by "Place of work". It can be assumed that for all of the students, both in Taiwan and in Europe, personal and career development are significant factors when considering specialty preferences. However, lifestyle after training completion did not appear to be as important among the group 
of Polish (European) students, who instead emphasized their passion for the work and a need for independent activity during specialty training. This may reflect both differences in economic status of doctors in Taiwan and in specialty training process. It could be supposed that the Taiwanese students perceive doctors as having a satisfying income, secure and stable jobs which satisfy their needs, and therefore their interest in lifestyle after training appears more important. Otherwise, the process of training may generally give them more independent work whereas in Poland independence during training might be something expected by students. However, this assumption would need further research.

Although some studies based on Taiwanese students have found expected income and the possibility of opening a private practice to be not as important as expected $[41,42]$ other studies have shown that the potential financial rewards after obtaining medical specialty are of high importance to students [12, 13, 37]. Our findings indicate that financial rewards are of high importance to this studied group: Future revenue and the possibility of opening a private practice, which brings supplemental income, were mentioned as essential criteria, followed by such factors as "Opportunities for professional career in healthcare entities" and "Place of work". In Poland, expected income is still a major issue for future doctors since the health system is underfinanced and salaries do not allow an acceptable standard of living to be achieved by working at only one position.

While the most preferable specialties in the present study were Surgery and Pediatrics, Wang et al. found them to be Internal Medicine and Surgery, with Pediatrics in the third place [42]. The students in the present study gave "Opportunity to create one's own medical practice", "The prestige of the chosen specialty" and "Place of work" as the most influential criteria for choosing Surgery, and "Intellectual qualities and competencies useful in practicing the specialty", "Opportunities for professional career in healthcare entities" and "Place of work" when choosing Pediatrics. In contrast, Wang et al. [42] report that students marked Personal intelligence/ability preference, Career opportunities and Lifestyle after completion of training as the most important criteria for Surgery, and Personal intelligence/ability preference, Career opportunities and Work independently after the training while when choosing Pediatrics. In the present study, students preferring surgery seemed more concerned about additional income, prestige and place of work compared to development of their personal traits, career and lifestyle in Wang et al. [42] It can be assumed that these variations are due to differences in economic status of doctors, which is probably much lower in Poland, resulting in students focusing more on economic issues than personal development and lifestyle. Our results are consistent with previous findings indicating that Surgery residents are more likely to be interested in modern technology, prestige and higher income [29]; however, these studies were not based on an
AHP approach. On the other hand, respondents preferring Pediatrics emphasized the development of intellectual abilities, career and place of work in both the present study and that of Wang et al. [42]. These similarities may occur because of the close resemblance in the work, the personality of those preferring Pediatrics [54] or the similarity of the financial rewards. However, this would need further research.

The use of AHP allowed detailed results to be obtained, which have scientific significance and practical value for the both University and health care in general. The results show not only the most important factors influencing choice of specialty but also the relative weight of each factor. This knowledge may be valuable for young physicians when making their decisions for a professional career, and for public services to assure the availability of an appropriate number of specialists in all medical domains. It could be used in medical career counseling, and may be used by government services to create strategies encouraging, supporting, and fostering student interest in specializing in under-supplied medical specialties. This study also provides the opportunity for further research on other factors and models influencing choice of specialty, as well as on the differences between countries in this regard. It also shows the possible applications of the AHP method in similar studies.

This study has some limitations. The group of examined students is quite small. It was planned and carried out with participation of sixth-year students attending one medical university, which restricts the possibility of generalizing the conclusions for the whole population of medical students in Poland or in Europe. However, the small size of the group was the result of the long interviewing procedure carried out with the students. In addition, the number of compared factors was above nine, which raised the probability of false responses; ideally this number should be between five and nine.

To conclude, the criteria examined in the study influence the choice of medical specialty to various degrees. When choosing medical specialties, students marked such qualities as personality, intellectual potential and aspirations as being the most important. What is more, the employed model found the most important criteria for choosing specialty to be "Opportunities for professional career in healthcare entities", "Place of work", "Opportunity to create one's own medical practice" and "Expected income". These results not only indicate which factors have the greatest influence on the choice of specialty but also suggest incentives that could be created to promote the development of their interests and influence their choice of medical specialty. Understanding the factors influencing the choice of medical specialty by students enables workforce planning to meet local and national healthcare needs and helps develop the educational process. This understanding is particularly important for Poland, as it has one of the most expensive medical education systems, with many of the graduates emigrating to western Europe after their course. 


\section{Acknowledgement}

We offer our warm thanks to all those who willingly participated in this study. We also wish to thank Edward Lowczowski, who helped with proofreading of the manuscript and dr Magdalena Kotlicka-Antczak for help in organizing the data collection. We also greatly thank the late Professor Jolanta Rabe-Jablonska for her support in this study.

\section{Disclosure statement}

No potential conflict of interest was reported by the authors.

\section{Funding}

This research did not receive any specific grant from funding agencies in the public, commercial, or not-forprofit sectors.

\section{References}

1. Kamalakanthan A., Jackson S., The Supply of Doctors in Australia: Is There A Shortage?, 2006; http://www.uq.edu. au/economics/abstract/341.pdf (accessed: 14.02.2018).

2. Fazel S., E.K, Specialty choice in UK junior doctors: Is psychiatry the least popular specialty for UK and international medical graduates?, "BMC Medical Education" 2009; 77 (9).

3. Forcier M.B., Simoens S., Giuffrida A., Impact, regulation and health policy implications of physician migration in OECD countries, "Human Resources for Health" 2004; 2 (1): 12.

4. Vujicic M. et al., The role of wages in the migration of health care professionals from developing countries, "Human Resources for Health" 2004; 2 (1): 3.

5. McAlister R.P. et al., Attrition in residents entering US obstetrics and gynecology residencies: analysis of National GME Census data, "American Journal of Obstetrics and Gynecology” 2008; 199 (5): 574 e1-576e1.

6. Longo W.E. et al., Attrition of categoric general surgery residents: results of a 20-year audit, "American Journal of Surgery" 2009; 197 (6): 774-778; discussion 779-780.

7. Riebschleger M. et al., Noncompletion in pediatric rheumatology fellowships, "Journal of Graduate Medical Education” 2014; 6 (1): 158-161.

8. Goldenberg M.N., Williams D.K., Spollen J.J., Stability of and factors related to medical student specialty choice of psychiatry, “Am. J. Psychiatry” 2017; 174 (9): 859-866.

9. Pawelczyk A.M. et al., Temperament traits and preference for surgical or nonsurgical specialties in year 6 medical students, "Teaching and Learning in Medicine" 2014; 26 (4): 387-392.

10. Soethout M., Heymans M., TenCate O., Career preference and medical students' biographical characteristics and academic achievement, "Medical Teacher" 2008; 30: e15-e30.

11. Fadem B.H. et al., Predicting medical specialty choice: A model based on students' records, "Journal of Medcial Education" 1984; 59 (5): 407-415.

12. Gorenflo D.W., Ruffin M.T.t., Sheets K.J., A multivariate model for specialty preference by medical students, "Journal of Family Practice" 1994; 39 (6): 570-576.
13. Reed V.A., Jernstedt G.C., Reber E.S., Understanding and improving medical student specialty choice: A synthesis of the literature using decision theory as a referent, "Teaching and Learning in Medicine" 2001; 13 (2): 117-129.

14. Smith V., Bethune C., Hurley K.F., Examining medical student specialty choice through a gender lens: An orientational qualitative study, "Teach Learn. Med." 2018; 30 (1): 33-44.

15. McGreevy J., Wiebe D., A preliminary measurement of the surgical personality, "American Journal of Surgery" 2002; 184 (2): 121-125.

16. Moore S., Katz B., Holder J., Machiavellianism and medical career choices, "Psychological Reports" 1995; 76 (3 Pt 1): 803-807.

17. Kwon O.Y., Park S.Y., Specialty choice preference of medical students according to personality traits by Five-Factor Model, “Korean J. Med. Educ.” 2016; 28 (1): 95-102.

18. Murdoch M.M. et al., Evaluating the psychometric properties of a scale to measure medical students' career-related values, "Academic Medicine" 2001; 76 (2): 157-165.

19. Schwartz M.D. et al., Medical student interest in internal medicine. Initial report of the Society of General Internal Medicine Interest Group Survey on Factors Influencing Career Choice in Internal Medicine, "Annals of Internal Medicine" 1991; 114 (1): 6-15.

20. Gotz K. et al., [Aspirations of medical students: "planning for a secure career" - results of an online-survey among students at five medical schools in Germany], "Deutsche medizinische Wochenschrift" 2011; 136 (6): 253-257.

21. Li J., Plastic surgery or primary care? Altruistic preferences and expected specialty choice of U.S. medical students, "J. Health Econ." 2018; 62: 45-59.

22. Azizzadeh A. et al., Factors influencing career choice among medical students interested in surgery, "Current Surgery" 2003; 60 (2): 210-213.

23. Kiker B.F., Zeh M., Relative income expectations, expected malpractice premium costs, and other determinants of physician specialty choice, "Journal of Health and Social Behavior" 1998; 39 (2): 152-167.

24. Hatem Mahmoud Shaheen Alahwal et al., Career counseling activities and choice of specialties among medical interns, "Bahrain Medical Bulletin" 2010; 32 (4).

25. Rehman A. et al., Pakistani medical students'specialty preference and the influencing factors, "JPMA. The Journal of the Pakistan Medical Association" 2011; 61 (7): 713-718.

26. Alers M. et al., Speciality preferences in Dutch medical students influenced by their anticipation on family responsibilities, "Perspectives on Medical Education" 2014; 3 (6): 443-454.

27. DeWitt D.E., Curtis J.R., Burke W., What influences career choices among graduates of a primary care training program?, "Journal of General Internal Medicine" 1998; 13 (4): 257-261.

28. Cleland J.A. et al., A survey of factors influencing career preference in new-entrant and exiting medical students from four UK medical schools, "BMC Medical Education" 2014; 14: 151.

29. Grigg M., Arora M., Diwan A., Australian medical students and their choice of surgery as a career: A review, 
"Australian and New Zeland Journal of Surgery" 2014; 84 (9): 653-655.

30. Kim Y.Y. et al., Factors associated with the specialty choice of Korean medical students: A cross-sectional survey, "Hum. Resour. Health" 2016; 14 (1): 45.

31. Gong B. et al., Influence of artificial intelligence on Canadian medical students' preference for radiology specialty: A National Survey Study, “Acad. Radiol.” 2019; 26 (4): 566-577.

32. Osborn H.A. et al., Primary care specialty career choice among Canadian medical students: Understanding the factors that influence their decisions, "Can. Fam. Physician" 2017; 63 (2): e107-e113.

33. Kopacz D.R., Grossman L.S., Klamen D.L., Medical students and AIDS: Knowledge, attitudes and implications for education, "Health Education Research" 1999; 14 (1): 1-6.

34. Newton D.A., Grayson M.S., Whitley T.W., What predicts medical student career choice?, "Journal of General Internal Medicine" 1998; 13 (3): 200-203.

35. Bonura E.M., Armstrong W.S., Increasing subspecialization in the field of infectious diseases: Evaluating challenges and strategies to move forward, "J. Infect. Dis." 2017; 216 (suppl. 5): S594-S599.

36. Lepiece B. et al., Social dominance theory and medical specialty choice, "Advances in Health Sciences Education: Theory and Practice" 2015.

37. Ibrahim M. et al., What factors influence British medical students' career intentions?, "Medical Teacher" 2014; 36 (12): 1064-1072.

38. Creed P.A., Searle J., Rogers M.E., Medical specialty prestige and lifestyle preferences for medical students, "Social Science and Medicine" 2010; 71 (6): 1084-1088.

39. Takeda Y. et al., Characteristic profiles among students and junior doctors with specific career preferences, "BMC Medical Education" 2013; 13 (Sep 12).

40. Valentino J., Blue A.V., Donnelly M.B., The most valuable critical incidents in a 4th-year acting internship in surgery, "Teaching and Learning in Medicine" 1999; 11: 75-79.

41. Chang P.Y. et al., Factors influencing medical students' choice of specialty, "J. Formos. Med. Assoc." 2006; 105 (6): 489-496.

42. Wang K.I. et al., Analysis of senior medical students' preferences in specialty choice a survey in a medical school in northern Taiwan, "Chang Gung Medical Journal" 2007; 30 (4): 339-353.

43. Adamus W., F.J. W., The evolution of shale gas development and energy security in Poland: Presenting a hierarchical choice of priorities, "Energy Research \& Social Science" 2016; 20: 168-178.

44. Adamus W., Gręda A., Multi-criteria decision support in solving the problems of organization and management, "Operations Research and Decisions" 2005; 2: 5-37.

45. Adamus W., Lasak P., Application of AHP to choose the location of surveillance of the financial market, "Bank and Credit" 2010; 41 (4): 73-101.

46. Wolfslehner B., Vacik H., Lexer M., Application of the analytic network process in multi-criteria analysis of sustainable forest management, "Forest Ecology and Management" 2005; 207: 165-166.

47. Adamus W., Adamus T., [Rating hospitals from the perspective of patients]. Article in Polish, "Zeszyty Naukowe Ochrony Zdrowia. Zdrowie Publiczne i Zarządzanie" 2012; 10 (4): 4-18.

48. Liberatore M.J., Nydick R.L., The analytic hierarchy process in medical and health care decision making: A literature review, "European Journal of Operational Research" 2008; 189 (1): 194-207.

49. Chang P.Y. et al., Factors influencing medical students' choice of specialt, "Journal of the Formosan Medical Association" 2006; 105 (6): 489-496.

50. 50. Saaty T.L., Decision Making for Leaders. The Analytic Hierarchy Process for Decisions in a Complex World, RWS Publications, Pittsburgh, PA 2001.

51. Saaty T.L., The Analytic Hierarchy Process: Planning, Priority Setting, Resource Allocation, McGraw-Hill International Book Co., New York-London 1980: xiii, 287.

52. Byun D.H., The AHP approach for selecting an automobile purchase model, "Information and Management" 2001; 38 : 289-297.

53. Hafeez K., Zhang Y., Malak N., Determining key capabilities of a firm using analytic hierarchy proces, "International Journal of Production Economics" 2002; 76: 39-51.

54. Bitran M. et al., [Influence of personality and learning styles in the choice of medical specialty], "Revista Medica de Chile" 2005; 133 (10): 1191-1199. 